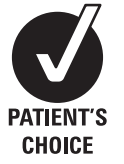

${ }^{1}$ Department of Physiotherapy, School of Healthcare Studies, Cardiff University, Ty Dewi Sant, Heath Park, UK; ${ }^{2}$ Department of Neurology, School of Medicine, Cardiff University Heath Park, Cardiff, UK; ${ }^{3}$ Department of Medical Genetics, School of Medicine, Cardiff University Heath Park, Cardiff, UK; ${ }^{4}$ Brain Repair Group, School of Biosciences, Cardiff University, Museum Avenue, Cardiff, UK

Correspondence to: Dr M Busse, Department of Physiotherapy, School of Healthcare Studies, Cardiff University, Ty Dewi Sant, Heath Park, Cardiff CF14 4XN, UK; busseme@cardiff.ac.uk

Received 25 February 2008 Revised 2 June 2008 Accepted 5 June 2008

\title{
Mobility and falls in people with Huntington's disease
}

\author{
M E Busse, ${ }^{1}$ C M Wiles, ${ }^{2}$ A E Rosser ${ }^{2,3,4}$
}

\section{ABSTRACT}

Objective: The aim of this study was to estimate the frequency of falls in people with Huntington's disease (HD) and make a preliminary assessment of tools appropriate for assessing the risk of falling.

Design: Observational study.

Setting: Hospital clinic.

Subjects: 24 people with HD.

Main measures: Balance was assessed using the Berg Balance Scale (BBS) and Timed "Up \& Go" (TUG) test. Walking speed over $10 \mathrm{~m}$ was recorded. Long-term monitoring of walking activity was undertaken. Unified Huntington Disease Rating Scale (UHDRS) motor, Functional Assessment Scale (FAS), Independence Scale (IS) and Total Functional Capacity (TFC) scores were obtained as well as data about falls and stumbles. Differences between "recurrent fallers" ( $\geqslant 2$ falls/year) and "non-fallers" ( $\leqslant 1$ fall/year) for the range of outcome measures were investigated and probabilities calculated. Results: Mean (SD) age (years) of people with HD $(\mathrm{n}=24)$ tested was $56.6(11.7)$ and BMl $\left(\mathrm{kg} / \mathrm{m}^{2}\right) 24.7$ (5.5). Median (range) UHDRS motor scores were 48 (28$80)$. Ten $(41.6 \%)$ patients reported $\leqslant 1$ fall and 14 $(58.3 \%) \geqslant 2$ falls in the previous 12 months. Recurrent fallers walked less $(p<0.01)$ and slower than non-fallers. Their balance (BBS) $(p<0.01)$ was worse and TUG scores were higher $(p<0.01)$. People with HD had increased risk of falls if TUG scores were $\geqslant 14 \mathrm{~s}$ or BBS scores $\leqslant 40$. Conclusion: A high proportion of $\mathrm{HD}$ patients have recurrent falls, and the BBS and TUG appear to be useful in falls risk assessment.

Huntington disease (HD) results in progressive loss of functional abilities. Despite reports highlighting falls-related injuries and associated balance problems,${ }^{1-3}$ there is no systematic research on falling and its risk factors in $\mathrm{HD}$ in the community. Formal assessment of falls is not part of the standard validated assessment protocols in widespread use.

The standard assessment tool for $\mathrm{HD}$ is the Unified Huntington Disease Rating Scale (UHDRS). ${ }^{4}$ The UHDRS comprises semiquantitative clinical scales to assess motor function, cognitive function, behavioural abnormalities and functional capacity. UHDRS motor scores have been found to be sensitive to change over time ${ }^{5}$ with higher scores indicating greater impairment for the motor assessment. The UHDRS functional scale comprises three components (functional assessment scale (FAS), the independence scale (IS), and the Total Functional Capacity (TFC)). Although UHDRS scores can be considered indicators of impairment and functional loss, their value in predicting likelihood of falls is unknown.

The Activities-Specific Balance Confidence Scale $(A B C)^{6}$ is a self-administered questionnaire used to assess fear of falling in older people and has discriminant ability to identify fallers from nonfallers and those who avoid activity due to fear of falling. ${ }^{7}$ Additionally clinical measurements of mobility and balance, such as the Timed Up and Go Test (TUG) ${ }^{8}$ and the Berg Balance Scale (BBS), are known to relate to falls' risk in other conditions. ${ }^{10}$ The TUG and the BBS have been reported to be useful in single cases of people with $\mathrm{HD}^{1}$ but have not been formally validated for this use. Although anecdote suggests that people with $\mathrm{HD}$ are at risk of falls and do fall, falls' rate does not appear to have been investigated in depth. We aim here to assess fall prevalence and consider the above-mentioned potential measures of increased fall risk in the HD population.

\section{METHODS}

\section{Subjects}

Patients with manifest HD attending the Cardiff HD clinic between December 2006 and November 2007 were offered participation in the study in accordance with local research ethics committee permissions (06/WSE03/70). All subjects provided informed consent prior to participation. Inclusion criteria were a genetically confirmed diagnosis of $\mathrm{HD}$, age over 18 , capacity for informed consent, no major concurrent psychiatric illness, presentation with motor signs and a score of 4 on the UHDRS motor diagnostic confidence rating.

Demographic data including age (years), and body mass index (BMI) $\left(\mathrm{kg} / \mathrm{m}^{2}\right)$ and current medication were obtained. Scores on the motor section of the Unified Huntington Disease Rating Scale (UHDRS motor), the Total Functional Capacity (TFC), the Functional Assessment Scale (FAS) and the Independence Scale were recorded.

\section{Balance and walking}

Patients were assessed using the Berg Balance Scale (BBS) (maximum score 56 indicating good balance) and the "Timed Up \& Go" (TUG) test. The modified Activities-Specific Balance Confidence (ABC-UK) Scale provided an estimate of balance confidence. Self-selected walking speed over $10 \mathrm{~m}$ was recorded in an indoor corridor. Stride length was also calculated. Long-term walking activity was recorded using using the Step Watch Step Activity Monitor (SAM) (Cymatech, Seattle, Washington) worn for seven consecutive $24 \mathrm{~h}$ periods. This device and protocol has been used previously in patients with chronic neurological disorders. ${ }^{11}$ Indices extracted were mean daily $24 \mathrm{~h}$ step count and highest average step count sustained over any continuous $60 \mathrm{~min}$ period (sustained activity). 


\section{Falls and stumbles}

Data were collected for falls and stumbles in the previous 12 months using a questionnaire. ${ }^{12}$ The questionnaire was completed by the patient with assistance from their main carer. Participants were categorised as recurrent fallers if they reported $\geqslant 2$ falls over the previous 12 months. If patients reported $\leqslant 1$ fall, they were not considered to be recurrent fallers. ${ }^{13}$

\section{Data analysis}

Descriptive statistics were used to quantify falls and scores on outcome measures. Independent $t$ tests, Mann-Whitney $U$ tests and $\chi^{2}$ tests were used where relevant to detect differences on outcome measures according to whether a person was a recurrent faller or non-faller. Logistic regression was used to plot the probability of falling for the each of the separate continuous falls risk outcome measures (ie, the BBS and the TUG). The alpha level was set at 0.05. The Statistical Package for the Social Sciences (SPSS) Version 12 (SPSS, Chicago) was used for all data analysis and Minitab Version 14 for graphing.

\section{Sample size}

A priori sample size calculations were conducted using WINPEPI software: ${ }^{14} 20$ subjects were sufficient to detect a standardised difference in outcome measures of 1.25 between recurrent fallers and non-fallers (independent $t$ test).

\section{RESULTS}

Twenty-four people with $\mathrm{HD}$ were recruited. Demographic data are presented in table 1 . The most common medications prescribed for this group were antichoreic medication $(41.6 \%$ of patients), benzodiazepines ( $16.6 \%$ of patients) and those with an antidepressant main action (50\% of patients).

Five $(20.8 \%)$ people reported no falls in the previous 12 months, and five (20.8\%) reported only one fall: thus 10 were classified "non-fallers." Fourteen (58.3\%) reported falling twice or more in the previous 12 months (classified as recurrent fallers). Of the recurrent fallers, $61.6 \%$ were also stumbling frequently, while in the non-fallers, $50 \%$ reported stumbling on

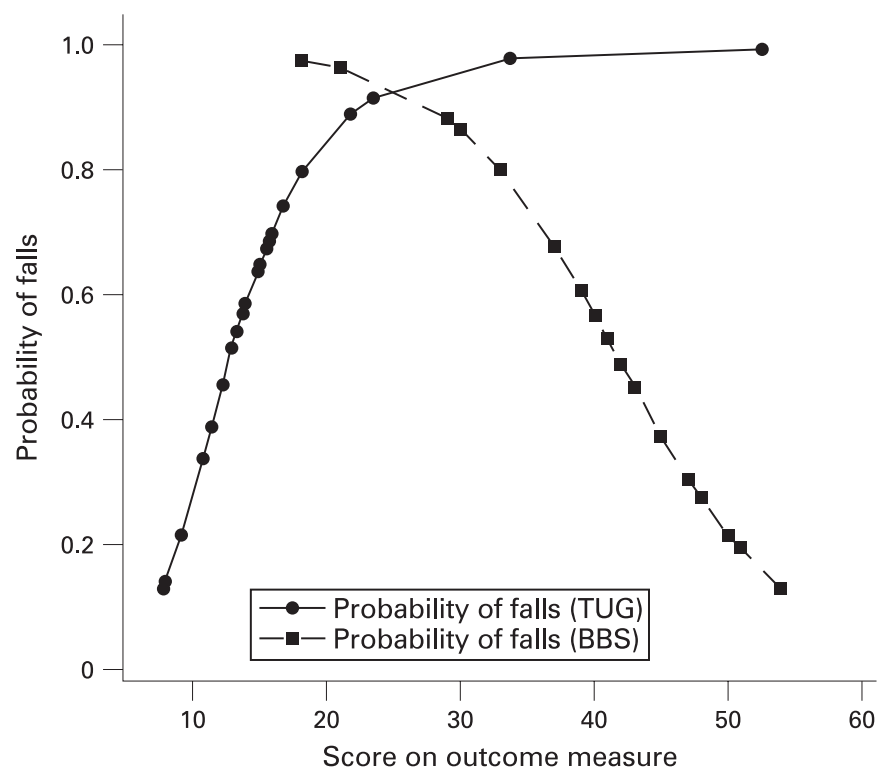

Figure 1 Score on continuous outcome measures (Timed "Up \& Go" (TUG) and Berg Balance Scale (BBS)) and related probability of falls. a regular basis. Table 1 shows the outcome scores for the whole group and non-fallers and recurrent fallers subgroups.

There were no differences in age, BMI or gender between those who were classified as recurrent fallers and those classified as non-fallers. There were no clear differences in frequency of prescription of the anti-choreic medication between fallers (6/ 14) and non-fallers (4/10) or bensodiasepines in the fallers $(3 / 14)$ compared with the non-fallers $(1 / 10)$ although the numbers were too small to analyse these data statistically.

Logistic regression identified the continuous variables of TUG (s) and BBS score as significant predictors of falls. The TUG and BBS were not entered into a combined logistic regression model due to the high correlations between the measures. Predicted probabilities for falling plotted against the continuous variables identified a classification cut-off for increased risk of falls if TUG scores were $\geqslant 14$ s or BBS scores $\leqslant 40$. Figure 1 shows the plots of the probabilities obtained for falls for the TUG and BBS scores against the continuous TUG and BBS scores.

\section{DISCUSSION}

This study confirms that people with manifest HD do fall regularly. Only $20.8 \%$ of people did not report any falls in the previous 12 months. Fallers took fewer steps and walked more slowly than non-fallers, and their balance (BBS and TUG scores) and balance confidence (ABC-UK) were worse. Scores for nonfallers $(n=10)$ and recurrent fallers $(n=14)$ were different for the IS and FAS but not for the other UHDRS-related clinical scores (including UHDRS motor). This study was not specifically powered to detect differences in the UHDRS motor scores.

The TUG and BBS scores both predicted probability of falling and may therefore be considered for use in people with HD. The susceptibility of the TUG to cognitive impairment may however limit its applicability in $\mathrm{HD}$; this test needs a clear understanding of the instructions as well as an interaction between patient, assessor and environmental setting. ${ }^{15}$ The BBS, developed primarily to evaluate balance in elderly people and people with stroke, may be more robust in those with cognitive impairment.

Recurrent fallers were less active than non-fallers (step count and sustained step counts) and less independent. Both step count and sustained step counts were statistically significantly different between fallers and non-fallers. While a daily step count recording may mistakenly register chorea as steps, therefore inflating the step count of subjects with worse chorea, the sustained walking step counts should be more robust. It is unclear whether the reduction in physical activity is related more to perceived balance and confidence or is a direct result of the motor impairments seen in $\mathrm{HD}$.

The importance of objective recordings is also an issue in the assessment of falls rate.

The extent to which carer bias may have influenced falls' reporting is unclear and emphasises the need for alternative methods of evaluation. Self-reported questionnaires are subject to bias, and failure to recall an injury is high using self report; calendar recording of falls events would be more accurate in recording falls and injuries. ${ }^{16}{ }^{17}$ While falls and stumbles do occur in healthy subjects, ${ }^{12}$ it would be unusual for healthy people to report recurrent falls. We attempted to minimise report failure by careful involvement of carers in questionnaire completion, but one might anticipate potential under-reporting. Such underreporting limits the usefulness of the dichotomised outcome $\leqslant 1$ or $\geqslant 2$ falls except that the latter probably indicates a group falling more often. Reliance on patient/carer recall or recording of falls could be objectively augmented by techniques such as automated event recording ${ }^{18}$ over prolonged periods (weeks). 
Table 1 Comparison of scores for all outcomes for the whole group and for the subgroups (non-fallers vs recurrent fallers)

\begin{tabular}{|c|c|c|c|}
\hline & Whole group & Subgroup: non-faller & Subgroup: recurrent faller \\
\hline Outcome & $\begin{array}{l}\text { Mean (SD) age } 56.6 \text { (11.7), BMI } \\
24.7(5.5) ; 16 \text { males: eight females }\end{array}$ & $\begin{array}{l}\text { Mean (SD) age } 55.2 \text { (6.8), BMI } 22.9 \\
(4.3) \text {; six males: four females }\end{array}$ & $\begin{array}{l}\text { Mean (SD) age } 57.6(14.4), \text { BMI } 25.9 \text { (6.1); } 10 \\
\text { males: four females }\end{array}$ \\
\hline $\begin{array}{l}\text { Unified Huntington's Disease Rating } \\
\text { Scale motor score } \dagger\end{array}$ & $48(28$ to 80$)$ & $43(28$ to 72$)$ & $\begin{array}{l}52 \text { (36 to } 68 \text { ) (approximate } 95 \% \mathrm{Cl} \text { of difference } \\
-19.7 \text { to } 3.9 \text { ) }\end{array}$ \\
\hline Total functional capacity $\dagger$ & 7 (3 to 11$)$ & $8(4$ to 11$)$ & $\begin{array}{l}5.5 \text { (3 to } 9 \text { ) (approximate } 95 \% \mathrm{Cl} \text { of difference } \\
-0.03 \text { to } 3.9 \text { ) }\end{array}$ \\
\hline Functional Assessment Scale $\uparrow$ & 18 (7 to 25$)$ & 21 (11 to 25$)$ & $\begin{array}{l}14(9 \text { to } 22)^{*} \text { (approximate } 95 \% \mathrm{Cl} \text { of difference } \\
1.5 \text { to } 10.1)\end{array}$ \\
\hline Independence scale: & 77.5 (50 to 95$)$ & $81.9(10.7)$ & $67.5(10.1)^{* *}(95 \% \mathrm{Cl}$ of difference 4.5 to 24.3$)$ \\
\hline Daily right step count: & $4978(2185)$ & $6729(1494)$ & $\begin{array}{l}3853(1796)^{* *}(95 \% \mathrm{Cl} \text { difference } 1376 \text { to } \\
4373 \text { steps) }\end{array}$ \\
\hline Steps/minute sustained for $60 \mathrm{~min}$ 末 & $24.4(9.4)$ & $30(6.6)$ & $\begin{array}{l}20(9)^{*}(95 \% \mathrm{Cl} \text { of difference } 2 \text { to } \\
17 \text { steps } / \mathrm{min})\end{array}$ \\
\hline Gait speed $(\mathrm{m} / \mathrm{s}) \star$ & $0.88(0.24)$ & $1.03(0.2)$ & $\begin{array}{l}0.8(0.2)^{*}(95 \% \mathrm{Cl} \text { of difference } 0.05 \text { to } \\
0.45 \mathrm{~m} / \mathrm{s})\end{array}$ \\
\hline $\begin{array}{l}\text { Activities-Specific Balance } \\
\text { Confidence Scale-UK (\%)\$ }\end{array}$ & $60.7(27.4)$ & 77.5 (13.9) & $\begin{array}{l}47.9(28.6)^{* *}(95 \% \mathrm{Cl} \text { of difference } 10.6 \text { to } \\
48.6 \%)\end{array}$ \\
\hline Berg Balance Scale $\dagger$ & $41(18$ to 54$)$ & 45 (33 to 54$)$ & $\begin{array}{l}38(18 \text { to } 48)^{* *} \text { (approximate } 95 \% \mathrm{Cl} \text { of } \\
\text { difference } 2.3 \text { to } 17.8 \text { ) }\end{array}$ \\
\hline “Timed Up \& Go" test $(\mathrm{s}) \dagger$ & $14.2(7.7$ to 52.6$)$ & $12.6(7.7$ to 16.6$)$ & $\begin{array}{l}15.6(7.7 \text { to } 52.6)^{* *} \text { (approximate } 95 \% \mathrm{Cl} \text { of } \\
\text { difference } 0.07 \text { to } 15.4 \mathrm{~s} \text { ) }\end{array}$ \\
\hline
\end{tabular}

Recurrent fallers and non-fallers were assessed for between-group differences.

${ }^{*}$ Significant difference between fallers and non-fallers at the 0.01 level (two-tailed).

${ }^{*}$ Significant difference at the 0.05 level (two-tailed).

$\dagger$ Median (range) data are presented.

Mean (SD) data are presented

Falls, injury and loss of independent ambulation are often factors that precipitate admission to nursing homes, ${ }^{3}$ and falls, risk of falls and basic falls management advice ${ }^{19}$ should also be considered a priority in people with HD. Falling in HD is likely to be multifactorial in origin, ${ }^{20}$ and factors such as home environment, medication and cognitive status also require further investigation. Reduced step count and physical activity as well as reduced scores on functional capacity and independence scales and reduced balance confidence may be indicative of a person at risk of falls. The BBS as well as the TUG also have potential as falls risk outcome measures in $\mathrm{HD}$.

Acknowledgements: The researchers would like to acknowledge the Physiotherapy Research Society for assistance with funding of travel expenses related to this study. The European Huntington's Disease Network and in particular K Price, J Naji and 0 Handley are acknowledged for their assistance with the "Registry" database and recruitment of HD patients. We would also like to acknowledge The Wellcome Trust Clinical Research Facility for the use of ward space for data collection and the participants and their family for agreeing to participate. Statistical advice was received from R Playle, Cardiff University.

Competing interests: None.

Ethics approval: Ethics approval was provided by the South East Wales Local Research Ethics Committee.

Patient consent: Obtained.

\section{REFERENCES}

1. Quinn L, Rao A. Physical therapy for people with Huntington disease: current perspectives and case report. Neurol Rep 2002;26:145-53.

2. Di Scipio WJ, Hannesson ME. Neuromuscular facilitation in the treatment of Huntington's chorea. Behav Neuropsychiatry 1970;2:13-14.

3. Wheelock VL, Tempkin T, Marder K, et al. Predictors of nursing home placement in Huntington disease. Neurology 2003;60:998-1001.
4. Quinn N, Brown R, Craufurd D, et al. Core Assessment Program for Intracerebral Transplantation in Huntington's Disease (CAPIT-HD). Mov Disord 1996;11:143-50.

5. Siesling S, van Vugt JP, Zwinderman KA, et al. Unified Huntington's disease rating scale: a follow up. Mov Disord 1998;13:915-19.

6. Powell LE, Myers AM. The Activities-Specific Balance Confidence (ABC) Scale. J Gerontol A Biol Sci Med Sci 1995;50A:28-34M.

7. Myers AM, Powell LE, Maki BE, et al. Psychological indicators of balance confidence: relationship to actual and perceived abilities. J Gerontol A Biol Sci Med Sci 1996;51:M37-43.

8. Podsiadlo D, Richardson S. The timed "Up \& Go": a test of basic functional mobility for frail elderly persons. J Am Geriatr Soc 1991;39:142-8.

9. Berg KO, Wood-Dauphinee SL, Williams Jl, et al. Measuring balance in the elderly: validation of an instrument. Can J Public Health 1992;83(2 Suppl):7-11S.

10. Chiu AY, Au-Yeung SS, Lo SK. A comparison of four functional tests in discriminating fallers from non-fallers in older people. Disabil Rehabil 2003;25:45-50.

11. Busse ME, Wiles CM, van Deursen RW. Community walking activity in neurological disorders with leg weakness. J Neurol Neurosurg Psychiatry 2006;77:359-62.

12. Wiles CM, Busse ME, Sampson CM, et al. Falls and stumbles in myotonic dystrophy. J Neurol Neurosurg Psychiatry 2006;77:393-6.

13. Gunter KB, White KN, Hayes WC, et al. Functional mobility discriminates nonfallers from one-time and frequent fallers. J Gerontol A Biol Sci Med Sci 2000;55:M672-6.

14. Abramson JH. WINPEPI (PEPI-for-Windows): computer programs for epidemiologists. Epidemiol Perspect Innov 2004;17;1:6.

15. Nordin E, Rosendahl E, Lundin-Olsson L. Timed "Up \& Go" test: reliability in olde people dependent in activities of daily living-focus on cognitive state. Phys Ther 2006;86:646-55

16. Cummings SR, Nevitt MC, Kidd S. Forgetting falls. The limited accuracy of recall of falls in the elderly. J Am Geriatr Soc 1988;36:613-16.

17. Mackenzie L, Byles J, D'Este C. Validation of self-reported fall events in intervention studies. Clin Rehabil 2006;20:331-9.

18. Bourke AK, O'Brien JV, Lyons GM. Evaluation of a threshold-based tri-axial accelerometer fall detection algorithm. Gait Posture 2007:26:194-9.

19. NICE. The assessment and prevention of falls in older people. 2004. http://www. nice.org.uk/guidance/index.jsp?action $=$ bylD\&r $=$ true\&o $=10956$ (accessed $19 \mathrm{Dec}$ 2007).

20. Bilney B, Morris ME, Perry A. Effectiveness of physiotherapy, occupational therapy, and speech pathology for people with Huntington's disease: a systematic review. Neurorehabil Neural Repair 2003;17:12-24. 